\title{
Predominant androgenic component in the stimulatory effect of dehydroepiandrosterone on bone mineral density in the rat
}

\author{
C Martel, A Sourla, G Pelletier, C Labrie, M Fournier, S Picard, \\ S Li, M Stojanovic and F Labrie \\ MRC Group in Molecular Endocrinology, CHUL Research Center and Laval University, Québec, Canada G1V 4G2 \\ (Requests for offprints should be addressed to F Labrie, Laboratory of Molecular Endocrinology, CHUL Research Center, 2705 Laurier Boulevard, Québec, \\ Canada G1V 4G2)
}

\begin{abstract}
In order to assess the relative roles of the androgenic and/or estrogenic components in the stimulatory effect of dehydroepiandrosterone (DHEA) on bone mineral content (BMC) and density (BMD), ovariectomized (OVX) female rats received DHEA administered alone or in combination with the antiandrogen flutamide (FLU) or the antiestrogen EM-800 for 12 months. We also evaluated, for comparison, the effect of estradiol $\left(E_{2}\right)$ and dihydrotestosterone (DHT) constantly released by Silastic implants as well as medroxyprogesterone acetate (MPA) released from poly(lactide-co-glycolide) microspheres. Femoral BMD was decreased by $11 \% 1$ year after OVX, but treatment of OVX animals with DHEA increased BMD to a value $8 \%$ above that of intact animals. The administration of FLU reversed by $76 \%$ the stimulatory effect of DHEA on femoral BMD and completely prevented the stimulatory effect of DHEA on total body and lumbar spine BMD. Similar results were obtained for BMC. On the other hand, treatment with the antiestrogen EM-800 did not reduce the action of DHEA on BMD or BMC. At the doses used, MPA, $E_{2}$ and DHT increased femoral BMD, but to a lesser degree than observed with DHEA. Bone histomorphometry measurements were also performed. While DHEA treatment partially reversed the marked inhibitory effect of OVX on the tibial trabecular bone volume, the administration of FLU inhibited by $51 \%(P<0 \cdot 01)$ the stimulatory effect of DHEA on this
\end{abstract}

parameter. The addition of EM-800 to DHEA, on the other hand, increased trabecular bone volume to a value similar to that of intact controls. DHEA administration markedly increased trabecular number while causing a marked decrease in the intertrabecular area. The above stimulatory effect of DHEA on trabecular number was reversed by $54 \%(P<0 \cdot 01)$ by the administration of FLU, which also reversed by $29 \%$ the decrease in intertrabecular area caused by DHEA administration. On the other hand, the addition of EM-800, while further decreasing the intertrabecular space achieved by DHEA treatment, also led to a further increase in trabecular number to a value not significantly different from that of intact control animals, suggesting an additional effect of EM-800 over that achieved by DHEA. Treatment with DHEA caused a 4-fold stimulation of serum alkaline phosphatase, a marker of bone formation, while the urinary excretion of hydroxyproline, a marker of bone resorption, was decreased by DHEA treatment. Treatment with DHEA and DHEA+EM-800 decreased serum cholesterol levels by 22 and $65 \%$ respectively, while the other treatments had no significant effect on this parameter. The present data indicate that the potent stimulatory effect of DHEA on bone in the rat is mainly due to the local formation of androgens in bone cells and their intracrine action in osteoblasts.

Journal of Endocrinology (1998) 157, 433-442

\section{Introduction}

Control of bone mass is a dynamic process achieved by tightly coupled bone formation and resorption mechanisms (Parfitt 1994). Multiple systemic and local factors, including cytokines, growth factors, vitamin D and sex steroids, are known to be involved in achieving and maintaining normal bone balance (Centrella et al. 1994). Androgens are thought to act mainly through stimulation of bone formation while estrogens are known to inhibit bone resorption and, secondarily, turnover. Orchiectomy has been reported to increase bone turnover in a manner similar to ovariectomy (OVX) and this change is prevented by androgen replacement (Vanderschueren et al. 1992). It is generally believed that the reduction in circulating estrogen levels at menopause is responsible for the accelerated bone loss in women (Stevenson et al. 1989) with the resulting increased risk of osteoporotic fractures (Ettinger et al. 1985). Estrogen replacement therapy, commonly used to treat or prevent osteoporosis, requires the addition of progestins to counteract the endometrial proliferation induced by estrogens. However, 
epidemiological data indicate that both estrogens and progestins increase the risk of breast cancer (Hunt et al. 1987, Colditz et al. 1995). It would thus be useful to develop hormone replacement therapy that is free of such risk.

Man is unusual, with other non-human primates, in having adrenals that secrete large amounts of the precursor steroids dehydroepiandrosterone (DHEA) and its sulfate DHEA-S (Labrie 1991, Labrie et al. 1988, 1989, 1995, 1996b 1997d). These inactive precursors are converted into potent androgens and/or estrogens in the peripheral intracrine tissues that possess the appropriate steroidogenic enzymes (Labrie 1991, Labrie et al. 1988, 1989, 1995, 1996b, 1997c,d). We recently demonstrated the stimulatory effect of percutaneous administration of DHEA on bone mineral content (BMC) and density (BMD) in postmenopausal women (Labrie et al. 1997c).

In order to assess the relative roles of the androgenic and/or estrogenic components of DHEA action, we studied the effect of 12 months of administration of DHEA, alone or in combination with the antiandrogen flutamide (FLU) or the antiestrogen EM-800 on BMC and $\mathrm{BMD}$, on bone histomorphometry as well as on other parameters of bone formation and turnover in the rat. On the basis of our recent data showing the high bioavailability of DHEA administered percutaneously (Labrie et al. 1996a) and in order to avoid the first passage of DHEA through the liver and thus minimize inactivation of the steroid as well as to reduce the potential impact on the liver metabolizing enzymes, DHEA was administered percutaneously. We also evaluated, for comparison, the effect of $17 \beta$ estradiol $\left(\mathrm{E}_{2}\right)$, dihydrotestosterone (DHT) and medroxyprogesterone acetate (MPA) on the same parameters.

\section{Materials and Methods}

\section{Animals and treatment}

Adult female Sprague-Dawley rats (Crl:CD(SD)Br) (Charles River Laboratory, St-Constant, Canada) weighing $230-310 \mathrm{~g}(278 \pm 10 \mathrm{~g}$, mean \pm S.E.M. $)$ at the start of dosing were used in this study. The age of the animals was 10-13 weeks at the start of dosing. The rats were acclimatized to the environmental conditions (temperature $22 \pm 2{ }^{\circ} \mathrm{C}$; $14 \mathrm{~h}$ light $/ 10 \mathrm{~h}$ darkness cycles; lights on at $0715 \mathrm{~h}$ ) for 2 weeks before the start of the experiment. The animals were housed two per cage and were allowed free access to tap water and a pelleted commercial diet (Agway ProLab 4018 (Agway County Food, Syracuse, NJ, USA) and Lab Diet no. 5002 (Ralston Purina, St Louis, MO, USA). The experiment was conducted in a Canadian Council on Animal Care (CCAC)-approved facility in accordance with the CCAC Guide for Care and Use of Experimental Animals.

A total of 112 rats were randomly distributed into eight groups of 14 animals as follows: (1) intact control;
(2) OVX control; (3) OVX+MPA; (4) $\mathrm{OVX}+\mathrm{E}_{2}$; (5) OVX+DHT; (6) OVX+DHEA; (7) OVX+DHEA+ FLU; (8) OVX+DHEA+EM-800. On the first day, the animals of the appropriate groups were bilaterally ovariectomized under isoflurane-induced anesthesia. One Silastic implant of $E_{2}$ or DHT was inserted subcutaneously in the dorsal area of each animal of the indicated groups in order to deliver constant levels of steroids. Implants, chosen in preliminary experiments to give low physiological levels of $\mathrm{E}_{2}$ and DHT, had the following size and steroid concentration: $\mathrm{E}_{2}\left(\mathrm{E}_{2}:\right.$ cholesterol $\left.(1: 250, \mathrm{w}: \mathrm{w})\right), 0.5 \mathrm{~cm}$ length, 0.125 inch $(0.313 \mathrm{~cm})$ outer diameter and 0.062 inch $(0.155 \mathrm{~cm})$ inner diameter; DHT (DHT:cholesterol (30:100, w:w)), $2 \cdot 5 \mathrm{~cm}$ length, $0 \cdot 125$ inch outer diameter and 0.062 inch inner diameter. During the course of the experiment, the $\mathrm{E}_{2}$ and DHT implants were replaced every 4 to 6 weeks.

MPA was released from poly(lactide-co-glycolide) microspheres $(30 \mathrm{mg})$ injected s.c. every 3 months in a solution made up of $2 \%$ carboxymethylcellulose, $1 \%$ Tween 80 and water (US patent no. 5,434,146). Treatment with FLU (4'-nitro-3'-trifluoromethylisobutyranilide; $7.5 \mathrm{mg}$; injected s.c. in $0.5 \mathrm{ml}$ twice daily), EM-800 ((+)-7-pivaloyloxy-3-(4'-pivaloyloxyphenyl)-4methyl-2-(4")-(2'"'-piperidinoethoxy)phenyl)-2H-benzopyran) $(250 \mu \mathrm{g}$; orally; $0.5 \mathrm{ml}$; once daily) (Gauthier et al. 1997, Luo et al. 1997, Simard et al. 1997) and DHEA $(30 \mathrm{mg}$; $0.5 \mathrm{ml}$; applied twice daily on an approximately $3 \mathrm{~cm} \times 3 \mathrm{~cm}$ shaved area of dorsal skin) was initiated on the morning of day 1 of the study. FLU and EM-800 were administered in a solution comprised of $4 \%$ ethanol, 4\% polyethylene glycol $600,1 \%$ gelatin and $0.9 \% \mathrm{NaCl}$, and DHEA was administered in 50\% ethanol-50\% propylene glycol. The sham intact, OVX controls and animals from groups 3 to 5 received a twice daily application of $0.5 \mathrm{ml}$ of the vehicle alone (50\% ethanol-50\% propylene glycol).

\section{Measurement of BMC and BMD}

After 12 months of treatment, 10 rats per group were anesthetized with diazepam $(4 \mathrm{mg} / \mathrm{kg})$ and ketamine $(40-45 \mathrm{mg} / \mathrm{kg}$ ), and the whole body skeleton as well as the right femur from each animal were scanned using dual-energy X-ray absorptiometry (QDR 2000-7·10C; Hologic, Waltham, MA, USA) and Regional High Resolution Scan software (Hologic). The scan field size used for the whole body was $28.110 \times 17.805 \mathrm{~cm}$, the resolution was $0.1511 \times 0.0761 \mathrm{~cm}$ and the scan speed was $0.3608 \mathrm{~mm} / \mathrm{s}$, and, for the femur, the scan field size was $5.080 \times 1.902 \mathrm{~cm}$, the resolution was $0.0254 \times 0.0127 \mathrm{~cm}$ and the scan speed was $0.0956 \mathrm{~mm} / \mathrm{s}$. The BMC and BMD of the whole body skeleton, lumbar spine (scanned at the levels of the vertebrae L1-L2-L3-L4) and femur were determined. 


\section{Bone histomorphometry}

At necropsy, the left tibia of five animals per group was collected for histomorphometric analysis. The bone specimens were freed from adhering soft tissue and fixed for $24 \mathrm{~h}$ in ice-cold 10\% phosphate-buffered formalin, before dehydration in a series of increasing ethanol concentrations. The fixed tissue samples were then washed in three changes of toluene and finally embedded undecalcified in pure methyl methacrylate, at low temperature, as previously described (Baron et al. 1983, Chappard et al. 1983, 1987).

Four series of four consecutive sections were cut at different levels of the proximal tibia of each animal using a Jung-type K microtome equipped with HK3 tungsten carbide knives. Longitudinal sections were cut at $4 \mathrm{~mm}$ thickness and stained with slight modifications of the modified Masson-Goldner trichrome method (Baron et al. 1983). Bone histomorphometric analysis was performed using a semi-automated image analysis system, the Bioquant Bone Morphometry System (Bioquant Meg IV system, R\&M Biometrics Corp., Nashville, TN, USA) and a SummaSketch (Summagraphics, Anaheim, CA, USA) digitalizing tablet in conjunction with a Leitz Aristoplan microscope (Leica, Canada).

All measurements were performed, beginning at more than $1.2 \mathrm{~mm}$ from the growth plate-metaphysial junction to exclude the primary spongiosa and thus restrict measurements to the secondary spongiosa (Kimmel \& Jee 1980). The bone parameters were calculated from twodimensional measurements of bone volume (bone area in $\mathrm{mm}^{2}$ ), cancellous bone area and bone surface (in $\mathrm{mm}^{2}$ ), as previously described (Parfitt et al. 1987, Ke et al. 1995). Specifically, the following measurements were performed: (1) trabecular bone volume (TBV) defined as the percentage of trabecular cancellous bone within the spongy space: $\mathrm{TBV}=(\mathrm{BV} / \mathrm{TV}) \times 100($ Parfitt et al. 1987, Ke et al. 1995), where $\mathrm{BV}$ is cancellous bone volume (in $\mathrm{mm}^{3}$ ), and TV is tissue volume (in $\mathrm{mm}^{3}$ ); (2) trabecular bone thickness (in $\mu \mathrm{m})(\mathrm{TbTh})$ corresponding to the mean trabecular thickness: $\mathrm{TbTh}=2 /(\mathrm{BS} / \mathrm{BV})$; (3) trabecular number (in number per $\mathrm{mm}$ ) ( $\mathrm{TrN})$; and (4) trabecular bone separation (in $\mu \mathrm{m})(\mathrm{TrSp})$, which was calculated according to the parallel plate model: $\mathrm{TbN}=((\mathrm{BV} / \mathrm{TV}) / 10) / \mathrm{TbTh}$, and $\mathrm{TbSp}=(1000 / \operatorname{TrN})-(\mathrm{TbTh})$.

\section{Urine and blood collection}

Collections of 24-h urine were made from unfasted animals a few days before necropsy in order to evaluate parameters such as creatinine and hydroxyproline excretion. On the day of necropsy, a blood sample was collected from the abdominal aorta from fasted animals (approximately $18 \mathrm{~h}$ ) and serum was used to measure biochemical parameters.

\section{Hormone measurements}

Serum luteinizing hormone (LH) was measured by double-antibody RIAs using rat hormones (LH-I-6 for iodination; LH-RP-2 as standard) and the rabbit antiserum anti-rLH-S-8 generously supplied by the National Pituitary Program (Baltimore, MD, USA).

\section{Alkaline phosphatase measurement}

Serum alkaline phosphatase was measured using the IL Monarch Chemistry System.

\section{Urinary hydroxyproline measurement}

Urinary hydroxyproline was measured on frozen 24-h urine samples collected from fed animals using the method described by Podenphant et al. (1984).

\section{Measurement of levels of gonadotropin-releasing hormone (GnRH) $m R N A$}

Brains were fixed by vascular perfusion with $200 \mathrm{ml} 4 \%$ $(\mathrm{w} / \mathrm{v})$ paraformaldehyde in $0.1 \mathrm{M}$ phosphate buffer $(\mathrm{pH}$ 7.4). They were then quickly frozen, and $10 \mu \mathrm{m}$ thick coronal sections were serially cut through an area extending from the preoptic area to the anterior hypothalamus. The sections were then mounted on to gelatin/poly-Llysine-coated slides. In situ hybridization was performed as described previously (Li \& Pelletier 1992b). The probe chosen was a synthetic deoxyribonucleotide complementary to the GnRH coding region of the rat cDNA (bases 102-149). This probe was synthesized in our laboratory and was labeled at the $3^{\prime}$ end with $\left[{ }^{35} \mathrm{~S}\right]$ thio $]$ dATP (1000 Ci/mmol; Amersham Co., Oakvill, Ont., Canada) and terminal deoxynucleotidyl transferase (BoehringerMannheim, Montreal, Que., Canada) to a specific activity of about $5000 \mathrm{Ci} / \mathrm{mmol}$. After hybridization, the sections were dehydrated and coated with liquid photographic emulsion (Kodak NTB-2). After 7 days of exposure, the sections were processed and stained with hematoxylin and eosin. To assess the specificity of the hybridization signal, consecutive sections were alternately hybridized with sense and antisense labeled oligonucleotide probes encoding rat GnRH (Li \& Pelletier 1992a,b). The counting of grains per labeled neuron was performed using a Zeiss optical system coupled to a Macintosh Computer (power pc7500/100) and NIH Image software (GrainTEMP V1·1). A neuron was considered specifically labeled if the number of grains overlying the cell exceeded 5 times the background level. For each experimental group, the number of silver grains per cell was calculated from 200 cells.

\section{Statistical analysis}

Data are expressed as mean \pm s.E.M. for data obtained from 9 to 14 animals per group. Statistical significance was determined according to the multiple-range test of Duncan-Kramer (Kramer 1956). 
A

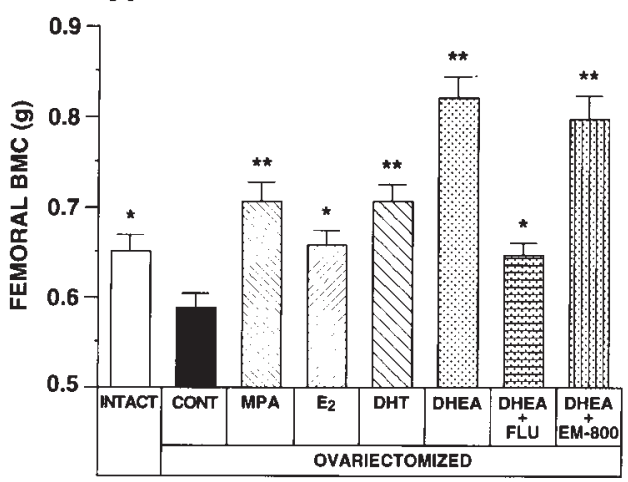

B

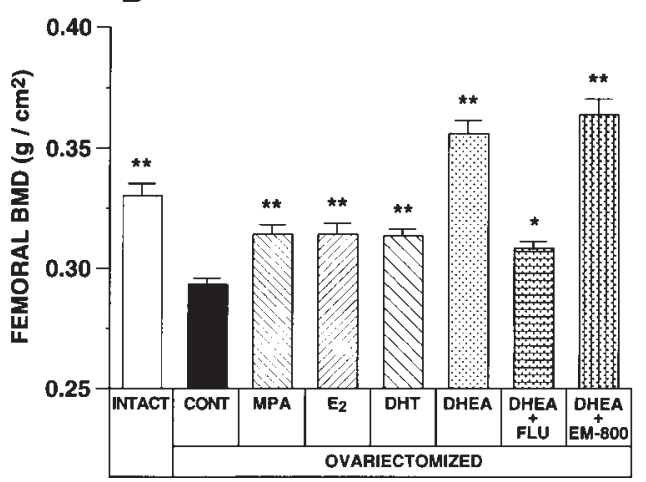

Figure 1 Effect of 12 months of treatment with MPA, $E_{2}$, DHT or DHEA alone or in combination with FLU or $\mathrm{EM}-800$ on femoral BMC (A) and BMD (B) in OVX rats. Intact animals are added as additional controls. Data are presented as mean \pm S.E.M. ${ }^{*} P<0 \cdot 05 ;{ }^{*} P<0 \cdot 01$ vs OVX control (Duncan-Kramer multiple-range test).

A

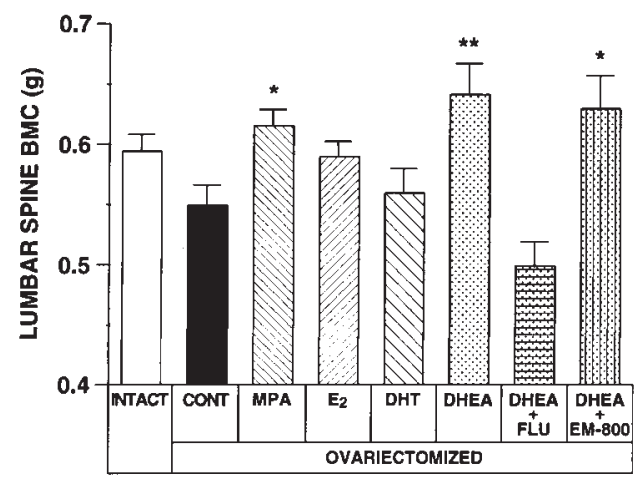

B

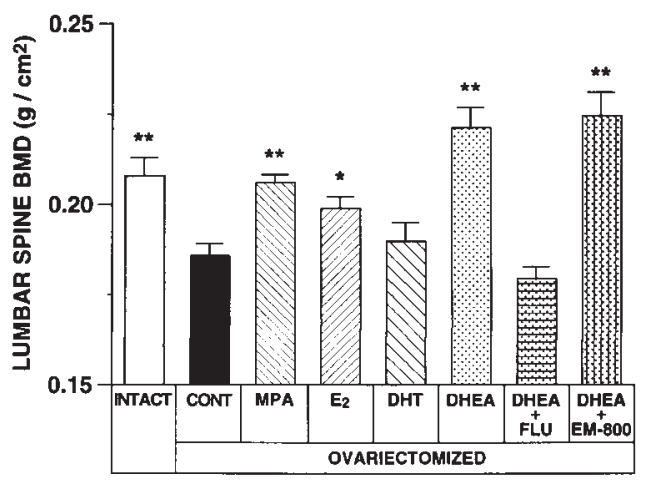

Figure 2 Effect of 12 months of treatment with MPA, $E_{2}$, DHT or DHEA alone or in combination with FLU or $\mathrm{EM}-800$ on lumbar spine $\mathrm{BMC}(\mathrm{A})$ and $\mathrm{BMD}(\mathrm{B})$ in $\mathrm{OVX}$ rats. Intact animals are added as additional controls. Data are presented as mean \pm S.E.M. ${ }^{*} P<0 \cdot 05 ;{ }^{* *} P<0 \cdot 01$ vs OVX control (Duncan-Kramer multiple-range test).

\section{Results}

One year after OVX, femoral BMC and BMD had decreased by $10 \%(P<0 \cdot 05)$ and $11 \%(P<0 \cdot 01)$ respectively (Fig. 1). Treatment with DHEA not only completely reversed the inhibitory effect of OVX but led to femoral BMC and BMD values $26 \%$ and $8 \%$ above those found in intact animals. Simultaneous treatment with the pure antiandrogen FLU reversed the stimulatory effect of DHEA on both femoral BMC and BMD by $76 \%$, while treatment with the pure antiestrogen EM-800 had no statistically significant inhibitory effect on the stimulation by DHEA of femoral BMC and BMD. At the doses used, treatment with MPA, $\mathrm{E}_{2}$ and DHT completely reversed the effect of OVX on BMC, and the same treatments reversed the inhibitory effect of OVX on BMD by $58 \%$ $(P<0 \cdot 01), 58 \%(P<0 \cdot 01)$ and $54 \%(P<0 \cdot 01)$ respectively.

When BMC and BMD were measured on the R1 (lumbar vertebrae 1-4) region of the lumbar spine, stimu- latory effects of DHEA similar to those observed for femoral BMC and BMD were observed (Fig. 2). After 1 year of treatment, OVX had decreased lumbar BMC and BMD by $7 \%$ (not significant) and $11 \%(P<0 \cdot 01)$ respectively. Treatment with MPA completely reversed the inhibitory effect of OVX on both BMC and BMD, and $\mathrm{E}_{2}$ reversed the inhibitory effect of OVX on lumbar BMD by $69 \%(P<0 \cdot 05)$. Treatment with DHEA, on the other hand, not only completely reversed the effect of OVX but led to lumbar BMC and BMD values $8 \%$ and $6 \%$ above those found in intact animals. Simultaneous administration of FLU completely reversed the stimulatory effect of DHEA on both parameters, but EM-800 had no significant effect on the stimulation by DHEA of lumbar BMC or BMD.

When the same measurements were performed on the total body skeleton, treatment with MPA, DHT and DHEA increased BMD by $7 \%(P<0 \cdot 01), 6 \%(P<0 \cdot 05)$ and $10 \%(P<0 \cdot 01)$ respectively (Fig. 3$)$. In agreement with 

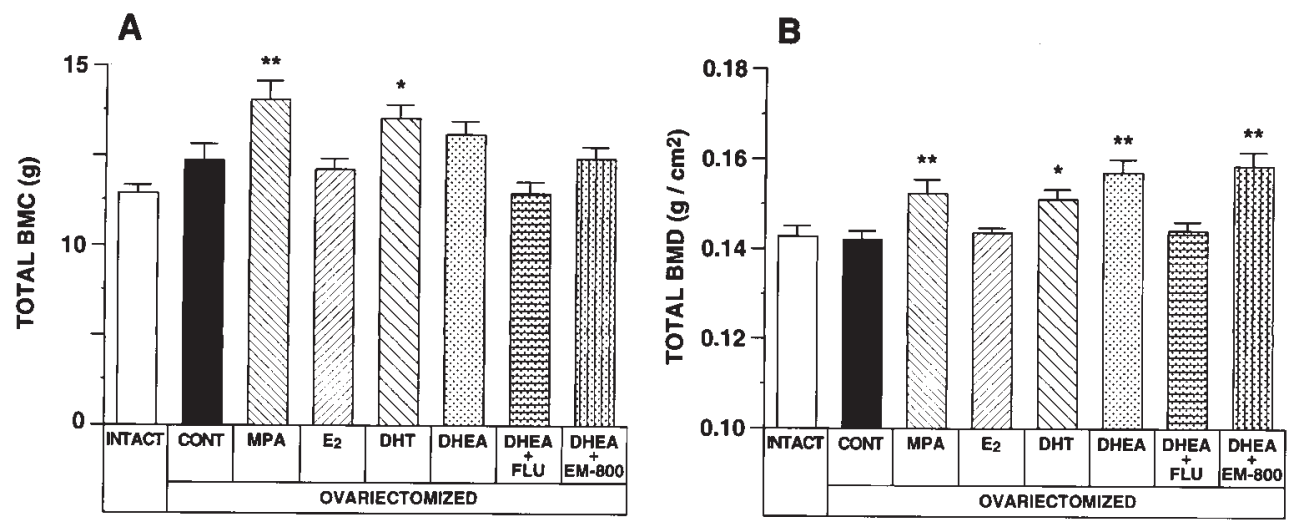

Figure 3 Effect of 12 months of treatment with MPA, $E_{2}$, DHT or DHEA alone or in combination with FLU or EM-800 on total body BMC (A) and BMD (B) in OVX rats. Intact animals are added as additional controls. Data are presented as mean \pm S.E.M. ${ }^{\star} P<0 \cdot 05 ;{ }^{*} P<0 \cdot 01$ vs OVX control (Duncan-Kramer multiple-range test).

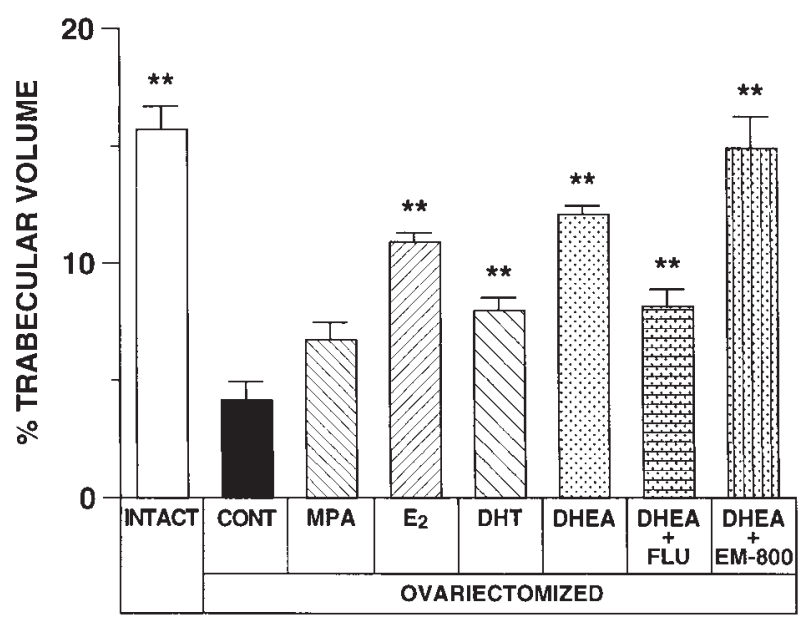

Figure 4 Effect of 12 months of treatment with $M P A, E_{2}$, DHT or DHEA alone or in combination with FLU or EM-800 on trabecular bone volume in OVX rats. Intact animals are added as additional controls. Data are presented as mean \pm S.E.M. ${ }^{* *} P<0 \cdot 01$ vs OVX control (Duncan-Kramer multiple-range test).

the results obtained on femoral and lumbar BMD, simultaneous administration of FLU completely reversed the stimulation by DHEA of total body BMD whereas EM-800 exerted no significant effect on the stimulatory effect of DHEA on this parameter.

At 12 months after OVX, marked decreases of $74 \%$ $(P<0 \cdot 01)$ and $69 \%(P<0 \cdot 01)$ in trabecular bone volume (Fig. 4) and trabecular bone number (Fig. 5) respectively were observed. Simultaneously, a marked increase in trabecular bone separation (Fig. 6) from a control value of $470 \pm 50$ to $1860 \pm 32 \mu \mathrm{m} \quad(P<0 \cdot 01)$ was measured. Treatment with $\mathrm{E}_{2}$, DHT or DHEA, at the doses used, all resulted in a partial reversal of the decrease in trabecular bone volume (Fig. 4) caused by OVX, by $61.6 \%$ $(P<0 \cdot 01), 47 \cdot 5 \%(P<0 \cdot 01)$ and $65 \cdot 2 \%(P<0 \cdot 01)$ respect-

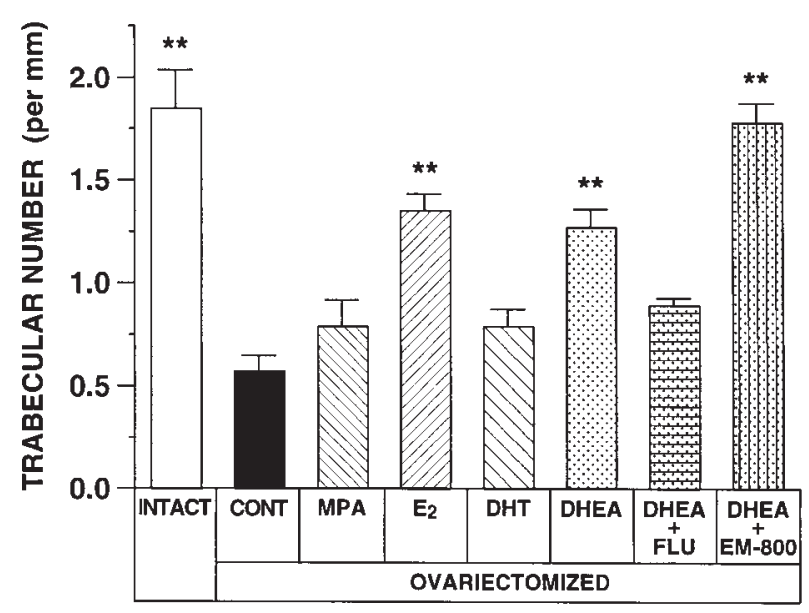

Figure 5 Effect of 12 months of treatment with MPA, $E_{2}$, DHT or DHEA alone or in combination with FLU or EM-800 on trabecular number in OVX rats. Intact animals are added as additional controls. Data are presented as mean \pm S.E.M. ${ }^{* * P} P<0 \cdot 01$ vs OVX control (Duncan-Kramer multiple-range test).

ively. In fact, treatment with DHEA increased the trabecular bone volume of the tibia to $11 \cdot 9 \pm 0 \cdot 6 \%$ from a control value of $4 \cdot 1 \pm 0 \cdot 7 \%(P<0 \cdot 01)$. The simultaneous administration of FLU reversed by $51 \%(P<0 \cdot 01)$ the stimulatory effect of DHEA on this parameter. EM-800, on the other hand, not only did not reduce the stimulatory effect of DHEA, but on the contrary, it further increased the trabecular bone volume to $14 \cdot 7 \pm 1 \cdot 4 \%$, a value similar to that found in intact controls.

A partial inhibition of the marked decrease in trabecular bone number (Fig. 5), observed 12 months after OVX, was achieved after treatment with $\mathrm{E}_{2}$ and DHEA, resulting in $137 \%$ (from $0.57 \pm 0.08$ to $1.35 \pm 0.09$ per $\mathrm{mm}$, $P<0.01$ ) and $123 \%$ (from $0.57 \pm 0.08$ to $1.27 \pm 0.1$ per $\mathrm{mm}, P<0 \cdot 01)$ higher values compared with OVX controls 


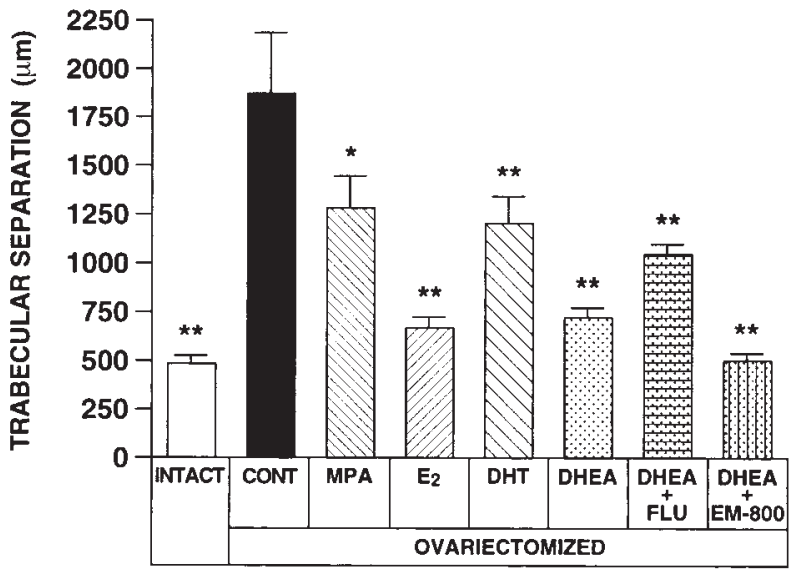

Figure 6 Effect of 12 months of treatment with MPA, $E_{2}$, DHT or DHEA alone or in combination with FLU or EM-800 on trabecular bone separation in OVX rats. Intact animals are added as additional controls. Data are presented as mean \pm S.E.M. ${ }^{*} P<0 \cdot 05$; ${ }^{*} P<0.01$ vs OVX control (Duncan-Kramer multiple-range test).

respectively. Treatment with MPA and DHT had no statistically significant effect on this parameter. On the other hand, the administration of FLU inhibited by $54 \%$ $(P<0 \cdot 01)$ the stimulatory effect of DHEA from $1 \cdot 27 \pm 0 \cdot 1$ to $0 \cdot 89 \pm 0.04$ per $\mathrm{mm}$, while simultaneous treatment with EM-800, on the contrary, resulted in an additional $28 \%$ increase in trabecular bone number $(P<0 \cdot 01)$ compared with that achieved by DHEA alone.

A partial reversal of the marked increase in trabecular separation (Fig. 6), observed 12 months after OVX, was achieved after treatment with MPA and DHT, which resulted in $41 \cdot 7 \%$ (to $1280 \pm 185 \mu \mathrm{m}, P<0 \cdot 05$ ) and $46 \cdot 7 \%$ (to $1210 \pm 135 \mu \mathrm{m}, P<0 \cdot 01$ ) decreases in trabecular bone separation compared with ovariectomized controls respectively. On the other hand, treatment with $\mathrm{E}_{2}$ or DHEA reversed by $85 \%$ and $82.5 \%$ respectively the effect of OVX on trabecular bone separation. Simultaneous administration of FLU reversed by $29 \%(P<0 \cdot 01)$ the inhibitory effect of DHEA on trabecular bone separation which thus increased from $713 \pm 60 \cdot 9$ to $1045 \pm 57 \cdot 5 \mu \mathrm{m}(P<0 \cdot 01)$. In contrast, the addition of EM-800 to DHEA treatment resulted in an additional $15 \%(P<0 \cdot 05)$ decrease in trabecular bone separation, compared with that achieved with DHEA alone, leading to values not different from those seen in intact controls.

Figure 7 illustrates the increase in trabecular bone volume in the proximal tibia metaphysis induced by DHEA in OVX treated animals (Fig. 7C) compared with OVX controls (Fig 7B), as well as the partial inhibition of the stimulatory effect of DHEA after the addition of FLU to DHEA treatment (Fig. 7D). On the other hand, administration of DHEA in combination with EM-800 resulted in a complete prevention of the OVXinduced osteopenia (Fig. 7E), the trabecular bone volume being comparable with that seen in intact controls (Fig. 7A).

The importance of the androgenic component of the stimulatory effect of DHEA on BMC and BMD is also supported by the effect of DHEA on markers of bone formation and resorption. The concentration of serum alkaline phosphatase, a marker of bone formation (Meunier et al. 1987, Lauffenburger et al. 1977), was increased from $51 \pm 4 \mathrm{IU} / 1$ in OVX controls to $201 \pm 25 \mathrm{IU} / 1$ in DHEA-treated animals, suggesting a stimulatory effect of DHEA on bone formation (Table 1). FLU reversed by $65 \%$ the stimulatory effect of DHEA on this parameter while EM-800 had no significant effect. At the doses used, $\mathrm{E}_{2}$, DHT and MPA had no significant effect on serum alkaline phosphatase.

Since hydroxyproline released during collagen degradation is not reutilized in collagen synthesis, it is a useful marker of collagen metabolism or osteoclastic bone resorption. In the present study, the urinary hydroxyproline/ creatinine ratio decreased from $11.7 \pm 1.2 \mu \mathrm{mol} / \mathrm{mmol}$ in OVX controls to $7 \cdot 3 \pm 1 \cdot 0 \mu \mathrm{mol} / \mathrm{mmol}(P<0 \cdot 05)$ in DHEA-treated rats (Table 1). The administration of FLU completely prevented the inhibitory effect of DHEA on this parameter while EM-800 had no statistically significant influence on the effect of DHEA. DHT decreased the urinary hydroxyproline/creatinine ratio to $7 \cdot 8 \pm 0 \cdot 7$ $(P<0 \cdot 05)$ while $\mathrm{E}_{2}$ and MPA had no significant effect.

Similarly, it can be seen in Table 1 that FLU reversed by $68 \%$ the $100 \%$ inhibitory effect of DHEA on the serum LH concentration in OVX animals while EM-800 had no influence on the potent inhibitory effect of DHEA. Treatment of OVX rats with MPA, $\mathrm{E}_{2}$ and DHT, at the doses used, caused 29, 33 and $56 \%$ decreases in serum $\mathrm{LH}$ levels respectively. The effects on serum LH levels correlated with the hypothalamic GnRH mRNA levels. Thus, 1 year after OVX, GnRH mRNA levels had increased by $23 \%(P<0 \cdot 01)$. At the doses used, treatment with MPA, $\mathrm{E}_{2}$ and DHT reversed the effect of OVX by $83 \%, 35 \%$ and $50 \%$ respectively (all $P<0 \cdot 01$ ). Treatment with DHEA reversed by $92 \%$ the effect of OVX, while simultaneous treatment with FLU prevented by $74 \%$ the inhibitory effect of DHEA on GnRH mRNA levels.

Serum cholesterol was reduced by $22 \%$ from $2 \cdot 29 \pm$ $0 \cdot 16$ to $1.78 \pm 0.16 \mathrm{mmol} / 1 \quad(P<0 \cdot 05)$ by DHEA treatment, an effect neutralized by concomitant treatment with the pure antiandrogen FLU. The addition of the pure antiestrogen EM-800, on the other hand, decreased total serum cholesterol further to $0.63 \pm 0.09 \mathrm{mmol} / 1(P<0 \cdot 01)$, thus reaching a $65 \%$ inhibitory effect. No statistically significant change was observed in serum triglyceride levels with any of the treatments used (Table 1).

\section{Discussion}

The present study shows that the DHEA-induced stimulation of femoral, lumbar spine and total body BMD and 

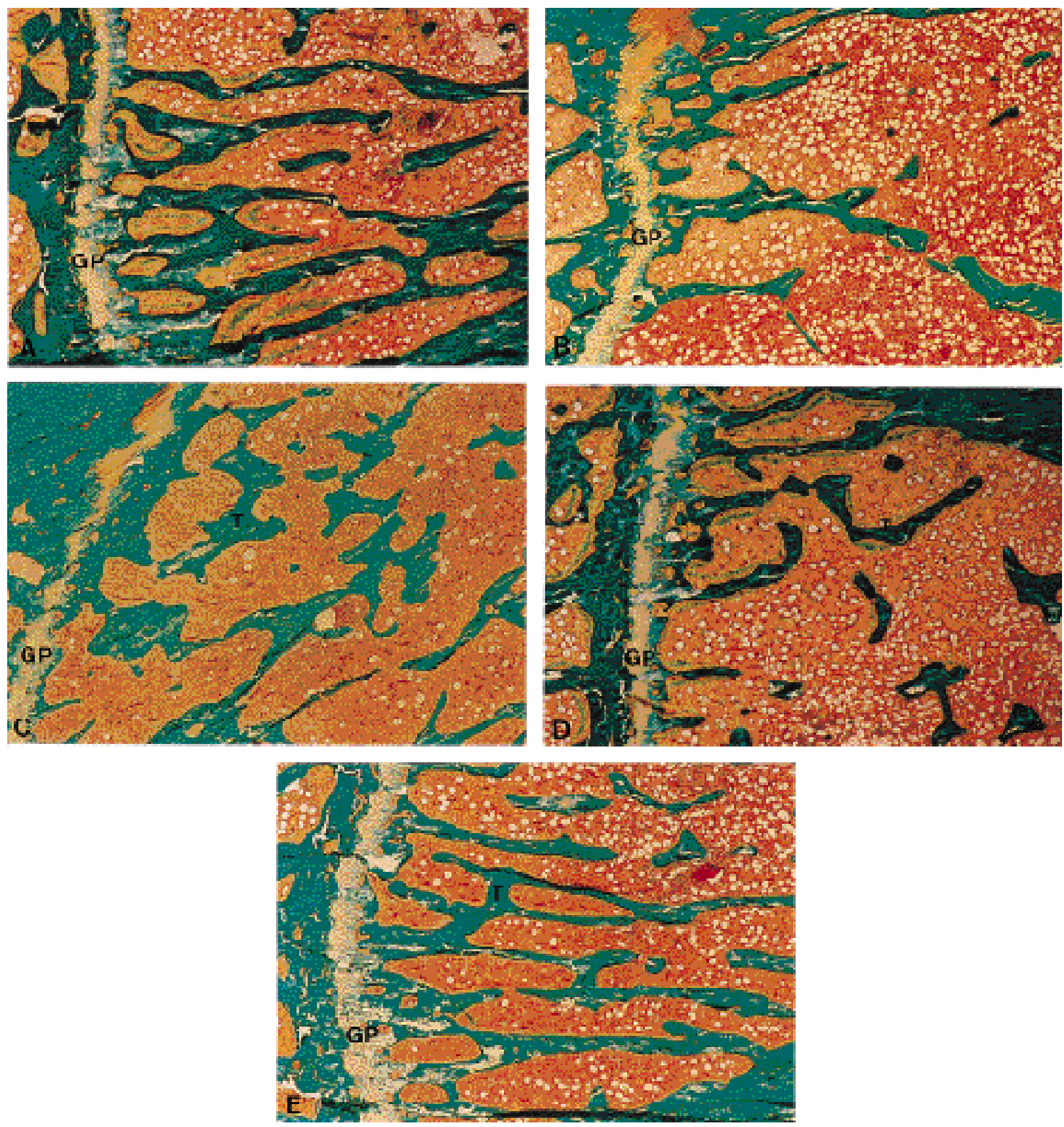

Figure 7 Proximal tibia metaphyses from intact control (A), OVX control (B) and OVX rats treated with DHEA alone (C) or in combination with FLU (D) or EM-800 (E). Note the reduced amount of trabecular bone (T) in OVX control animals (B), and the significant increase in trabecular bone volume (T) induced after DHEA administration (C). The addition of FLU to DHEA partially blocked the effect of DHEA on the trabecular bone volume (D), whereas the combination of DHEA and EM-800 provided complete protection against the OVX-associated bone loss. Modified Masson-Goldner trichrome method; magnification $\times 80$. T, trabeculae; GP, growth plate.

BMC is accompanied by an increase in serum alkaline phosphatase concentration, a marker of bone formation, and a decrease in urinary hydroxyproline excretion, a marker of bone resorption. While the administration of the antiestrogen EM-800 did not interfere with the stimu- latory effect of DHEA, the administration of the pure antiandrogen FLU partially or completely reversed, depending upon the parameter studied, the stimulatory effect of DHEA, thus supporting the predominant androgenic component of DHEA action. The present study also 
Table 1 Effect of 12 months of treatment with MPA, E $E_{2}$ DHT or DHEA alone or in combination with FLU or EM-800 on serum and urinary parameters as well as on GnRH mRNA levels in the hypothalamus. Values are means \pm S.E.M.

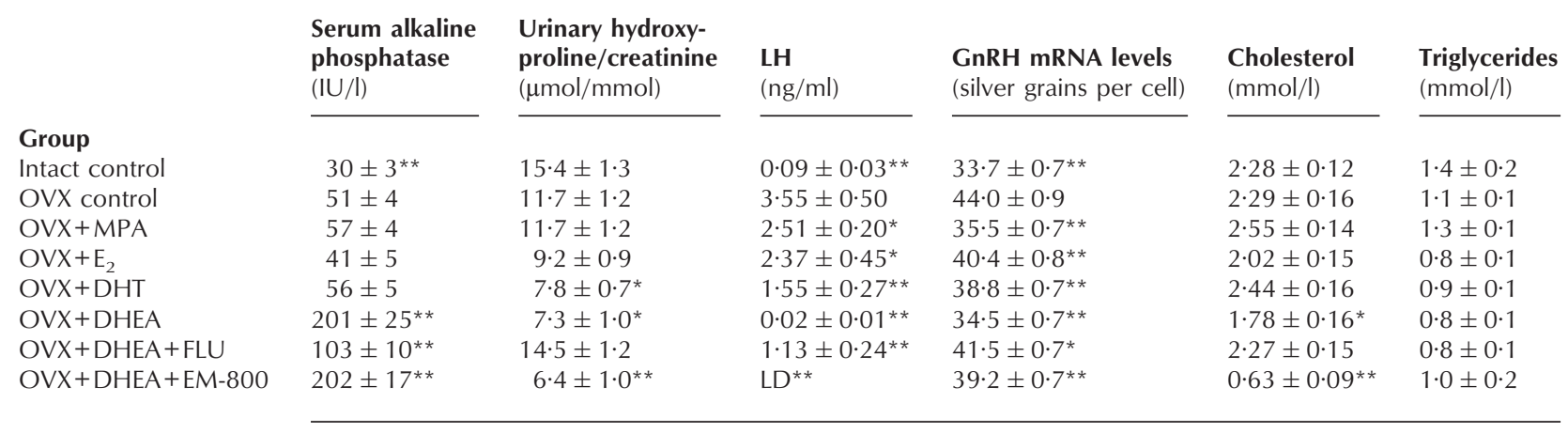

LD, limit of detection: $0 \cdot 01 \mathrm{ng} / \mathrm{ml}$

${ }^{*} P<0 \cdot 05 ;{ }^{*} P<0 \cdot 01$ vs OVX control (Duncan-Kramer multiple-range test).

shows a significant decrease in serum cholesterol, suggesting that DHEA treatment may exert positive effects on serum lipids in addition to the important effects observed on bone.

The bone loss observed at menopause in women is believed to be related to an increase in the rate of bone resorption which is not fully compensated for by the secondary increase in bone formation. In fact, both bone formation and bone resorption are increased in osteoporosis and suppressed by estrogen replacement therapy. The inhibitory effect of estrogen replacement on bone formation is thus believed to result from a coupled mechanism between bone resorption and bone formation, such that the primary estrogen-induced reduction in bone resorption entrains a reduction in bone formation (Parfitt 1984).

Cancellous bone strength and subsequent resistance to fracture do not only depend upon the total amount of cancellous bone but also on the trabecular microstructure, as determined by the number, size and distribution of the trabeculae. The loss of ovarian function in postmenopausal women is accompanied by a significant decrease in total trabecular bone volume (Melsen et al. 1978, Vakamatsou et al. 1985), mainly related to a decrease in the number and, to a lesser degree, the width of the trabeculae (Weinstein \& Hutson 1987). On the other hand, Parfitt et al. (1987) did not observe a significant reduction in trabecular thickness associated with trabecular bone loss during aging. The spatial arrangement of the trabeculae described by trabecular density and separation also largely affects the resistance of bone and provides information about the possible risk of fractures among osteoporotic patients (Parfitt et al. 1987).

Not all postmenopausal women suffer from osteoporosis-related bone fractures, suggesting heterogeneity of sensitivity to estrogens and/or the involvement of other hormones or estrogen-independent mechanisms in bone pathophysiology especially osteoporosis (Davidson et al. 1983, Nordin et al. 1985). The non-estrogenic component might well be related to the androgens synthesized in the osteoblasts from DHEA (Labrie 1991, Labrie et al. 1997a). There is, in fact, marked heterogeneity in the fall in serum DHEA levels during aging (Labrie et al. 1997b). In the present study, the androgenic stimulatory effect of DHEA was observed on almost all the bone histomorphometric parameters studied. DHEA thus resulted in a significant increase in trabecular bone volume as well as trabecular number, while it decreased the intertrabecular area. FLU reversed the above effects of DHEA, indicating that DHEA exerts most of its action through formation of androgens. However, incomplete prevention by FLU of the effect of DHEA on the same parameters may suggest an estrogen-like or another mechanism of DHEA action (Chesnut et al. 1983, Komm et al. 1988) or an insufficient dose of the antiandrogen.

It should be mentioned that the addition of EM-800 to DHEA treatment, not only did not antagonize the stimulatory action of DHEA on bone, but even showed an important additive effect on many parameters. These additional effects pertain to trabecular bone volume, trabecular number and trabecular separation. Such data suggest a positive action of EM-800 on bone. In fact, our preliminary data show that EM-800 prevents loss of BMD in OVX rats. This stimulatory effect of EM-800 on bone could explain the above observations of a positive effect of EM-800 on the stimulatory effect of DHEA on many parameters of bone metabolism.

The transformation of DHEA into estrogens by osteoblasts has also been reported (Nawata et al. 1995), and the presence of estrogen, androgen and progesterone receptors has been described in osteoblasts (Eriksen et al. 1988, Komm et al. 1988). DHEA administration significantly reduced or totally prevented the OVX-induced cancellous bone osteopenia in rats (Nawata et al. 1995), whereas a non-estrogenic effect of DHEA-S on bone has also been suggested following the observation of Miklos (1995) who reported a more severe decrease in DHEA-S production in 
postmenopausal osteoporotic women than in those with no evidence of osteoporosis.

Prolonged estrogen deficiency in rats is accompanied by a decrease in bone formation after an initial compensatory increase measured early after OVX (Turner et al. 1987). In addition, Tobias et al. (1991) and Chow et al. (1992) found that estrogen administration to OVX rats increased trabecular bone formation. The present finding of an increase in trabecular bone volume, associated with increased trabecular number coupled with the knowledge of the decreased trabecular thickness seen after estrogen administration, suggests a DHEA-induced increase in bone formation mediated by DHEA-derived androgens. MPA also induced a significant decrease in trabecular separation, although no final increase in cancellous bone volume was observed, a finding that may be related to the low dose of MPA administered.

The present data clearly suggest the potential of a new approach using DHEA to prevent and treat problems associated with menopause, especially osteoporosis. The inhibition of serum cholesterol by DHEA treatment suggests additional benefits on the serum lipid profile.

\section{Acknowledgements}

The authors wish to thank Diane Bastien, Louise Mailloux, Nancy Dubé and Alain St-Pierre for technical assistance.

\section{References}

Baron R, Vignery A, Neff L, Silverglate A \& Maria AS 1983 In Bone Histomorphometry: Techniques and Interpretation, pp 13-36. Boca Raton: CRC Press.

Centrella M, Horowitz MC, Wozney JM \& McCarthy TL 1994 Transforming growth factor- $\beta$ gene family members and bone. Endocrine Review 15 27-39.

Chappard D, Alexandre C, Camps M, Montheard JP \& Riffat G 1983 Embedding iliac bone biopsies at low temperature using glycol and methyl methacrylates. Stain Technology 58 299-308.

Chappard D, Palle S, Alexandre C, Vico L \& Riffat G 1987 Bone embedding in pure methyl methacrylate at low temperature preserves enzyme activities. Acta Histochemica 81 183-190.

Chesnut CH, Ivey JL, Gruber HE, Matthews M, Nelp WB, Sisom K \& Baylink DJ 1983 Stanozolol in postmenopausal osteoporosis: therapeutic efficacy and possible mechanisms of action. Metabolism 32 571-580.

Chow JW, Lean JM \& Chambers TJ 199217 Beta-estradiol stimulates cancellous bone formation in female rats. Endocrinology 130 3025-3032.

Colditz GA, Hankinson SE, Hunter DJ, Willett WC, Manson JE, Stampfer MJ, Hennekens C, Rosner B \& Speizer FE 1995 The use of estrogens and progestins and the risk of breast cancer in postmenopausal women. New England Journal of Medicine 332 1589-1593.

Davidson BJ, Riggs BL, Wahner HW \& Judd HL 1983 Endogenous cortisol and sex steroids in patients with osteoporotic spinal functions. Obstetrical Gynecology 61 275-278.
Eriksen EF, Colvard DS, Berg NJ, Graham ML, Mann KG, Spelsberg TC \& Riggs BL 1988 Evidence of estrogen receptors in normal human osteoblast-like cells. Science 241 84-86.

Ettinger B, Genant HK \& Cann CE 1985 Long-term estrogen replacement therapy prevents bone loss and fractures. Annals of Internal Medicine 102 319-324.

Gauthier S, Caron B, Cloutier J, Dory YL, Favre A, Larouche D, Mailhot J, Ouellet C, Schwerdtfeger A, Leblanc G, Martel C, Simard J, Mérand Y, Bélanger A, Labrie C \& Labrie F 1997 (S)-(+)-\{4-[7-(2,2-dimethyl-1-oxopropoly)-4-methyl-2-\{4-[2-(1piperidiny)ethocy]nyl-2H-1-benzopyran-3-yl]phenyl $\}-1-$ benzopyran-3-yl]phenyl\}-2,2-dimethylpropanoate (EM-800): a highly potent, specific and orally active non-steroidal antiestrogen. Journal of Medicinal Chemistry 40 2117-2122.

Hunt K, Vessey M, McPherson K \& Coleman M 1987 Long-term surveillance of mortality and cancer incidence in women receiving hormone replacement therapy. British Journal of Obstetrics and Gynecology 94 620-635.

Ke HZ, Simmons HA, Pirie CM, Crawford TD \& Thompson DD 1995 Droloxifene, a new estrogen antagonist/agonist, prevents bone loss in ovariectomized rats. Endocrinology 136 2435-2441.

Kimmel DB \& Jee WS 1980 A quantitative histologic analysis of the growing long bone metaphysis. Calcified Tissue International 32 113-122.

Komm BS, Terpening CM, Benz DJ, Graeme KA, Gallegos A, Korc M, Greene GL, O'Malley BW \& Haussler MR 1988 Estrogen binding, receptor mRNA, and biologic response in osteoblast-like osteosarcoma cells. Science 241 81-84.

Kramer CY 1956 Extension of multiple range tests to group means with unique numbers of replications. Biometrics 12 307-310.

Labrie F 1991 Intracrinology. Molecular and Cellular Endocrinology 78 C113-C118.

Labrie C, Bélanger A \& Labrie F 1988 Androgenic activity of dehydroepiandrosterone and androstenedione in the rat ventral prostate. Endocrinology 123 1412-1417.

Labrie C, Simard J, Zhao HF, Bélanger A, Pelletier G \& Labrie F 1989 Stimulation of androgen-dependent gene expression by the adrenal precursors dehydroepiandrosterone and androstenedione in the rat ventral prostate. Endocrinology 124 2745-2754.

Labrie F, Bélanger A, Simard J, Luu-The V \& Labrie C 1995 DHEA and peripheral androgen and estrogen formation: intracrinology. Annals of the New York Academy of Sciences 774 16-28.

Labrie C, Flamand M, Bélanger A \& Labrie F 1996a High bioavailability of DHEA administered percutaneously in the rat. Journal of Endocrinology 150 S107-S118.

Labrie F, Simard J, Luu-The V, Bélanger A, Pelletier G, Morel Y, Mebarki F, Sanchez R, Durocher F, Turgeon C, Labrie Y, Rhéaume E, Labrie C \& Lachance Y 1996 b The 3ß-hydroxysteroid dehydrogenase/isomerase gene family: lessons from type II 33-HSD congenital deficiency. In Signal Transduction in Testicular Cells. Ernst Schering Research Foundation Workshop, pp 185-218. Eds V Hansson, FO Levy \& K Taskén. Berlin, Heidelberg, New York: Springer-Verlag.

Labrie F, Bélanger A, Cusan L \& Candas B 1997a Physiological changes in DHEA are not reflected by the serum levels of active androgens and estrogens but of their metabolites: intracrinology. Journal of Clinical Endocrinology and Metabolism 82 2403-2409.

Labrie F, Bélanger A, Cusan L, Gomez JL \& Candas B 19976 Marked decline in serum concentrations of adrenal $\mathrm{C}_{19}$ sex steroid precursors and conjugated androgen metabolites during aging. Journal of Clinical Endocrinology and Metabolism 82 2396-2402.

Labrie F, Diamond P, Cusan L, Gomez JL \& Bélanger A 1997c Effect of 12-month DHEA replacement therapy on bone, vaginum, and endometrium in postmenopausal women. Journal of Clinical Endocrinology and Metabolism 82 3498-3505.

Labrie F, Luu-The V, Lin SX, Labrie C, Simard J, Breton R \& Bélanger A $1997 d$ The key role of $17 \beta-H S D$ in sex steroid biology. Steroids 62 148-158. 
Lauffenburger T, Olah AJ, Dambacher MA, Guncaga J, Lentner C \& Haas HG 1977 Bone remodeling and calcium metabolism: a correlated histomorphometric, calcium kinetic, and biochemical study in patients with osteoporosis and Paget's disease. Metabolism 26 589-606.

Li S \& Pelletier G 1992a Dopamine regulation of gonadotropinreleasing hormone $(\mathrm{GnRH})$ gene expression in the female rat brain. Neuroscience Letters 146 207-210.

Li S \& Pelletier G $1992 b$ Role of dopamine in the regulation of gonadotropin-releasing hormone in the male rat brain as studied by in situ hybridization. Endocrinology 131 395-399.

Luo S, Martel C, Sourla A, Gauthier S, Mérand Y, Bélanger A, Labrie C \& Labrie F 1997 Comparative effects of 28-day treatment with the new antiestrogen EM-800 and tamoxifen on estrogensensitive parameters in the intact mouse. International Journal of Cancer 73 381-391.

Melsen F, Melsen B, Mosekilde L \& Bergmann S 1978 Histomorphometric analysis of normal bone from the iliac crest. Acta Pathologica and Microbiologica Scandinavica 86 70-81.

Meunier PJ, Salson C \& Mathieu L 1987 Skeletal distribution and biochemical parameters of Paget's disease. Clinical Orthopaedics and Related Research 217 33-44.

Miklos S 1995 Dehydroepiandrosterone sulfate in the diagnosis of osteoporosis. Acta BioMedica de L'ateneo Parmense 66 139-146.

Nawata H, Tanaka S, Tanaka S, Takayanagi R, Sakai Y, Yanase T, Ikuyama S \& Haji M 1995 Aromatase in bone cell: association with osteoporosis in postmenopausal women. Journal of Steroid Biochemistry and Molecular Biology 53 165-174.

Nordin BEC, Robertson A, Seamark RF, Bridges A, Philcox JC, Need AG, Horowitz M, Morris HA \& Deam S 1985 The relation between calcium absorption, serum dehydroepiandrosterone, and vertebral mineral density in postmenopausal women. Journal of Clinical Endocrinology and Metabolism 60 651-657.

Parfitt AM 1984 The cellular basis of bone remodeling: the quantum concept reexamined in light of recent advances in the cell biology of bone. Calcified Tissue International 36 Suppl. 1 S37-S45.

Parfitt AM 1994 Osteonal and hemi-osteonal remodeling: the spatial and temporal framework for signal traffic in adult human. Journal of Cellular Biochemistry 55 273-286.
Parfitt AM, Drezner MK, Glorieux FH, Kanis JA, Malluche H, Meunier PJ, Ott SM \& Recker RR 1987 Bone histomorphometry: standardization of nomenclature, symbols, and units. Report of the ASBMR Histomorphometry Nomenclature Committee. Journal of Bone Mineral Research 2 595-610.

Podenphant J, Larsen NE \& Christiansen C 1984 An easy and reliable method for determination of urinary hydroxyproline. Clinica Chimica Acta 142 145-148.

Simard J, Labrie C, Bélanger A, Gauthier S, Singh SM, Mérand Y \& Labrie F 1997 Characterization of the effects of the novel non-steroidal antiestrogen EM-800 on basal and estrogeninduced proliferation of T-47D, ZR-75-1 and MCF-7 human breasts cancer cells in vitro. International Journal of Cancer $\mathbf{7 3}$ 104-112.

Stevenson JL, Lees B, Devenport M, Cust MP \& Ganger KF 1989 Determinants of bone density in normal women: risk factors for future osteoporosis? British Medical Journal 298 924-928.

Tobias JH, Chow J, Colston KW \& Chambers TJ 1991 High concentrations of $17 \beta$-estradiol stimulate trabecular bone formation in adult female rats. Endocrinology 128 408-412.

Turner RT, Vandersteenhoven JJ \& Bell NJ 1987 The effects of ovariectomy and $17 \beta$-estradiol on cortical bone histomorphometry in growing rats. Journal of Bone and Mineral Research 2 115-122.

Vakamatsou E, Villanueva HA, Stanciu J, Sudhaker RD \& Parfitt AM 1985 Calcified Tissue International 37 594-597.

Vanderschueren D, Van Herck E, Suiker AMH, Visser WJ, Schot LPC \& Bouillon R 1992 Bone and mineral metabolism in aged male rats: short and long term effects of androgen deficiency. Endocrinology $1302906-2916$.

Weinstein RS \& Hutson MS 1987 Decreased trabecular width and increased trabecular spacing contribute to bone loss with aging. Bone 8 137-142.

Received 19 August 1997

Revised manuscript received 15 January 1998

Accepted 2 February 1998 